\title{
Yarrowia lipolytica Growth Under Increased Air Pressure: Influence on Enzyme Production
}

\author{
Marlene Lopes • Nelma Gomes • Manuel Mota • \\ Isabel Belo
}

Received: 21 July 2008 / Accepted: 2 September 2008 /

Published online: 19 September 2008

(C) Humana Press 2008

\begin{abstract}
Improvement of microbial cell cultures oxygenation can be achieved by the increase of total air pressure, which increases oxygen solubility in the medium. In this work, a pressurized bioreactor was used for Yarrowia lipolytica batch cultivation under increased air pressure from 1 to 6 bar. Cell growth was strongly enhanced by the pressure rise. Fivefold and 3.4-fold increases in the biomass production and in specific growth rate, respectively, were observed under 6 bar. The increase of oxygen availability caused the induction of the antioxidant enzyme superoxide dismutase, which indicates that the defensive mechanisms of the cells against oxidative stress were effective and cells could cope with increased pressure. The pregrowth of $Y$. lipolytica under increased pressure conditions did not affect the lipase production ability of the cells. Moreover, the extracellular lipase activity increased $96 \%$ using a 5-bar air pressure instead of air at 1bar pressure during the enzyme production phase. Thus, air pressure increase in bioreactors is an effective mean of cell mass and enzyme productivity enhancement in bioprocess based in Y. lipolytica cultures.
\end{abstract}

Keywords Yarrowia lipolytica $\cdot$ Lipase $\cdot$ Oxidative stress $\cdot$ Oxygen $\cdot$ Pressure

\section{Introduction}

Yarrowia lipolytica is a nonconventional yeast, nontoxic, that can grow to very high densities [1]. It is most used in studies of the biodegradative pathways for a variety of hydrophobic compounds including alkanes, oils, and fatty acids [2] and thus for its capacity to produce lipid-degrading enzymes, such as lipases.

The amount of oxygen available in culture media to $Y$. lipolytica is an important parameter since this organism is strictly aerobic. Previous work demonstrated that hyperbaric air could be successfully applied to yeast cultivation, as a way of improving

M. Lopes $\cdot$ N. Gomes $\cdot$ M. Mota $\cdot$ I. Belo $(\bowtie)$

IBB-Institute for Biotechnology and Bioengineering, Centre for Biological Engineering,

Universidade do Minho, Campus de Gualtar, 4710-057 Braga, Portugal

e-mail: ibelo@deb.uminho.pt 
the oxygen transfer rate (OTR) to aerobic cultures [3-5]. Moreover, the energy and cost efficiencies of high-pressure fermentation for industrial application have already been demonstrated [6].

In industrial bioreactors, levels and gradients of total and partial pressures are considerably higher than on the laboratory scale. Thus, cells in bioreactors are often exposed to $\mathrm{O}_{2}$ partial pressures higher than 210 mbar (corresponding to air at 1 bar). In many cases, increased $\mathrm{O}_{2}$ partial pressure (higher than approximately 1 bar) is toxic to aerobic cultures and inhibits microbial growth and product formation [7]. During the reduction of molecular oxygen to water through acceptance of four electrons, reactive oxygen species (ROS) such as superoxide anion radical $\left(\mathrm{O}_{2}^{-}\right)$, hydrogen peroxide $\left(\mathrm{H}_{2} \mathrm{O}_{2}\right)$, and hydroxyl radical (HO·) are generated. The ROS may give rise to damage of enzymes, nucleic acids, or lipids [8]. To counter oxidative stress, cells constitutively express enzymes that detoxify the ROS and repair the damage caused by them. Antioxidant enzymes, such as catalase and superoxide dismutase (SOD), constitute the primary defenses of the cells because they are responsible for transforming these reactive oxygen species into nonreactive ones [9].

The aim of this work is to investigate whether increasing air pressures may lead to increasing biomass yields of Y. lipolytica W29, without giving rise to oxidative stress. Thus, the ability of the strain to induce antioxidant enzymes as a response to increased oxygen partial pressure was also assessed. Moreover, this paper reports an investigation into the influence of a preadaptation phase of cells to hyperbaric conditions on the lipase production by Y. lipolytica cells.

\section{Material and Methods}

\section{Strain and Media}

Y. lipolytica W29 (ATCC 20460) was grown in yeast extract peptone dextrose (YPD) medium. The lipase production medium was composed of $6.7 \mathrm{~g} \mathrm{l}^{-1}$ yeast nitrogen base (Pronadisa, 1545.1), $7 \mathrm{~g} \mathrm{l}^{-1}$ olive oil, $5 \mathrm{~g}^{-1}$ arabic gum, and $400 \mathrm{mM}$ Tris- $\mathrm{HCl}$ buffer, $\mathrm{pH} 7.2$.

\section{Operating Conditions}

Yeast cells were pregrown in 250-ml Erlenmeyer flasks filled with $100 \mathrm{ml}$ of the YPD medium at $140 \mathrm{rpm}$, at $27^{\circ} \mathrm{C}$ of temperature, and for $24 \mathrm{~h}$. Batch cultivations were carried out using a $600-\mathrm{ml}$ stainless steel stirred tank bioreactor (4563, Parr Instruments, USA), with $400 \mathrm{ml}$ of YPD media, at $27^{\circ} \mathrm{C}$, and $400 \mathrm{rpm}$ in order to assess the effect of air and oxygen pressure in cellular growth and on antioxidant enzyme induction. Compressed air was continuously sparged into the culture at an aeration rate of $1 \mathrm{vvm}$. Such a large air flow-rate volume ratio was chosen according with previous studies which assures that the liquid phase was near saturated on oxygen for this reactor and for the stirring rate and range of pressure values used [10]. The values of air pressure studied were from 1 to 6 bar. The operating pressure was set by the manipulation of the pressure of the inlet air and the regulatory valve position in the exit gas line. The reactor was equipped with a pressure transducer to monitor total internal pressure. An experiment in an Erlenmeyer flask $(500 \mathrm{ml})$ with $200 \mathrm{ml}$ of YPD medium, under atmospheric pressure (1 bar), and an agitation rate of $140 \mathrm{rpm}$ was used as a control. With the aim of investigating the influence of a 
preadaptation phase of cells to hyperbaric conditions on the lipase production by $Y$. lipolytica cells, experiments were conducted in the pressurized bioreactor in which the lipase production phase was preceded by a 24-h growth in YPD medium at 1 or 5 bar of total air pressure.

Analytical Methods

Culture samples were collected for analysis of cell concentration (optical density at $600 \mathrm{~nm}$ and cell number and converted to g cell dry per liter), total soluble protein, glucose consumption, and enzymatic assays. Total soluble protein was obtained by Bradford's method. Glucose was determined using the 3,5-dinitrosalycilic acid method. Extracellular lipase was measured in the sample supernatant using $p$-nitrophenyl-butyrate in sodium acetate buffer $50 \mathrm{mM}$ at $\mathrm{pH} 5.6$ as a substrate, at $37^{\circ} \mathrm{C}$ for $15 \mathrm{~min}$. One unit of activity was defined as the amount of enzyme that produces $1 \mu \mathrm{mol}$ of $p$-nitrophenol per minute under assay conditions. Protease in cell-free samples was quantified using $0.5 \%(w / v)$ azocasein in acetate buffer as substrate at $\mathrm{pH} 5.0$, at $37^{\circ} \mathrm{C}$ for $40 \mathrm{~min}$. One unit of activity was defined as the amount of enzyme that causes an increase of 0.01 of absorbance relative to the blank per minute under assay conditions.

The antioxidant enzymes were measured after cell disruption and dialysis of cell extracts, which were obtained as described elsewhere [11]. Catalase was assayed using the method described by Beers and Sizer [12] and SOD was quantified by the method of Marklund and Marklund [13].

\section{Results and Discussion}

\section{Air Effects on Cell Growth}

Typical batch growth curves and glucose consumption profiles for the experiments under increased air pressure and atmospheric pressure are shown in Fig. 1. The application of a 6bar stimulated cell growth compared to the atmospheric conditions.
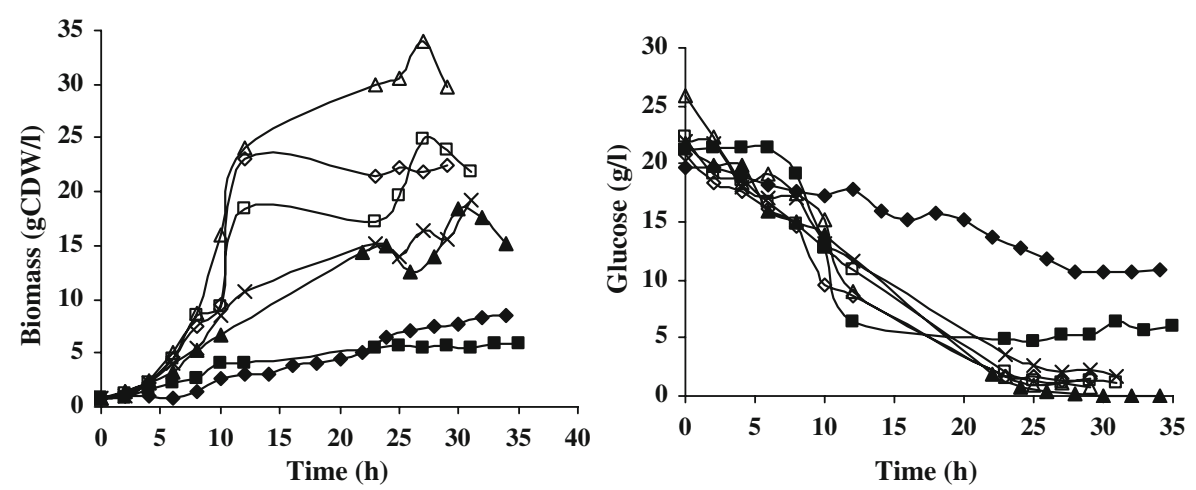

Fig. 1 Batch growth and glucose consumption of $Y$. lipolytica at atmospheric pressure (filled diamonds) and in hyperbaric reactor under pressures of 1 bar (filled squares), 2 bar (filled triangles), 3 bar (x marks), 4 bar (empty squares), 5 bar (empty diamonds), and 6 bar (empty triangles) 
The oxygen availability increase imposed by pressure raise had a clear positive effect on this yeast metabolism since the biomass production was enhanced and reached its maximal value for an air pressure of 6 bar. An increase of the cell dry weight at 6 bar of 3.5- and fivefold was obtained compared with the experiments under atmospheric pressure in the control essay and in the bioreactor at 1 bar, respectively.

The results described above are in accordance with the previous work of Lopes et al. [14], in which no cellular activity inhibition by air pressure increase was detected in batch cultures of $Y$. lipolytica, albeit a different culture medium without glucose and a different bioreactor were used. In experiments under atmospheric pressure and 1 bar of air pressure, glucose was not totally consumed. On the other hand, the raise of air pressure up to 6 bar led to a complete consumption of glucose.

Thus, the use of increased air pressure might be exploited to improve the biomass yield and productivity of $Y$. lipolytica W29 (Table 1). With 6-bar air pressure, biomass yields increased $67.8 \%$ and $86.4 \%$ compared with the experiments under atmospheric pressure (control) and 1 bar, respectively.

Also, a 4.1-fold improvement in biomass productivity was obtained with the increase of air pressure up to 6 bar compared to the control. Other nonconventional yeasts such as Pichia pastoris and Kluyveromyces marxianus were successfully cultivated under increased air pressure with significant improvements on biomass productivity [5, 11].

However, for yeasts with respiro-fermentative metabolic pathways, like Saccharomyces cerevisiae, the increase of air pressure led to a decrease on biomass productivity for a batch mode of operation [15]. In fact, for this yeast, air pressure increase showed to be useful for fed-batch mode of operation at operating conditions that allow fully respiratory metabolism and with a pressure increase program that enabled cellular adaptation to hyperbaric conditions [10]. This shows that microorganisms react differently to the air pressure raise, depending also on other culture conditions [4, 7, 16-18].

The specific growth rate of $Y$. lipolytica was clearly enhanced by the increase of air pressure. An increase of 6 bar led to a 3.4- and 1.7-fold increase in specific growth rate under atmospheric pressure and 1 bar, respectively. Due to the high oxygen mass transfer rate, the cells had more oxygen in the medium giving higher growth rates, and less time is necessary to obtain maximum cell concentration. The improvement of specific cellular growth of $Y$. lipolytica by OTR enhancement trough other means than pressure was previously observed, as is the case of oxygen carrier use, like perfluorocarbons [19].

It is clear from these results that pressure had no inhibitory effects on the growth of this yeast strain. An increase of air pressure up to 6 bar might successfully be applied to the improvement of the biomass production of Y. lipolytica W29.

Table 1 Changes in biomass yield, specific growth rate, and productivity with air pressure in batch experiments.

\begin{tabular}{lccc}
\hline Pressure (bar) & $Y_{\mathrm{x} / \mathrm{s}}(\mathrm{g}$ cells/g glucose $), \%$ & $\mu\left(\mathrm{h}^{-1}\right)$ & $P(\mathrm{~g}$ cells/1·h $)$ \\
\hline Control & 53.3 & 0.09 & 0.25 \\
1 & 34.7 & 0.18 & 0.17 \\
2 & 70.2 & 0.19 & 0.45 \\
3 & 96.7 & 0.23 & 0.62 \\
4 & 104.1 & 0.26 & 0.71 \\
5 & 117.9 & 0.28 & 0.77 \\
6 & 121.1 & 0.31 & 1.02 \\
\hline
\end{tabular}


Through the optical microscopic observation of the cells, it was found that the cells displayed a typical oval form in all assays up to 6 bar (data not shown). The results demonstrated that cell exposure to increased air pressure did not induce hyphae formation as reported by other authors as a result of oxidative stress due to chemical agents [20].

\section{Pressure Effect on Antioxidant Enzyme Activities}

To examine eventual effects of oxygen toxicity on yeast cells, with the increase in oxygen partial pressure, the changes of intracellular antioxidant enzyme activities under different air pressures were determined. Figure 2 presents the data of the catalase and SOD-specific activities, measured at the end of the cell cultivation under hyperbaric conditions.

Superoxide-dismutase-specific activity was induced by air pressure increase to a maximum at 6 bar. An increase of the SOD-specific activity at 6 bar (1.26 bar of oxygen partial pressure) of 53.4-fold was obtained compared with the experiments under 1 bar. This shows the ability of Y. lipolytica cells to respond to the increase of reactive oxygen species formation caused by hyperoxygenation. The adaptive response of the yeast Y. lipolytica to the oxidative stress induced by the oxidants like hydrogen peroxide, menadione, and juglone has been shown to be associated with an increase in the activity of cellular superoxide dismutase and other main enzymes involved in cell defense against oxidative stress [21]. In the herein presented work, the SOD induction showed the cell sensitivity to high dissolved oxygen concentrations. However, as no cell growth inhibition was observed under pressurized conditions, it is quite safe to state that the cells of the strain used can cope with such high air pressure values up to 6 bar that corresponds to a sixfold increase in oxygen solubility in the medium.

The influence of total air and oxygen pressure increase on the catalase activity is not clear; thus, it seems that this enzyme plays a minor role in the defensive mechanisms against the oxidative stress caused by oxygen partial pressure increase, for Y. lipolytica W29.

This is to our knowledge the first report on the response of SOD and catalase response to increased air-oxygen pressure in Y. lipolytica strains. These results demonstrate that the raise of air pressure could be also applied to SOD production, once it is most induced.
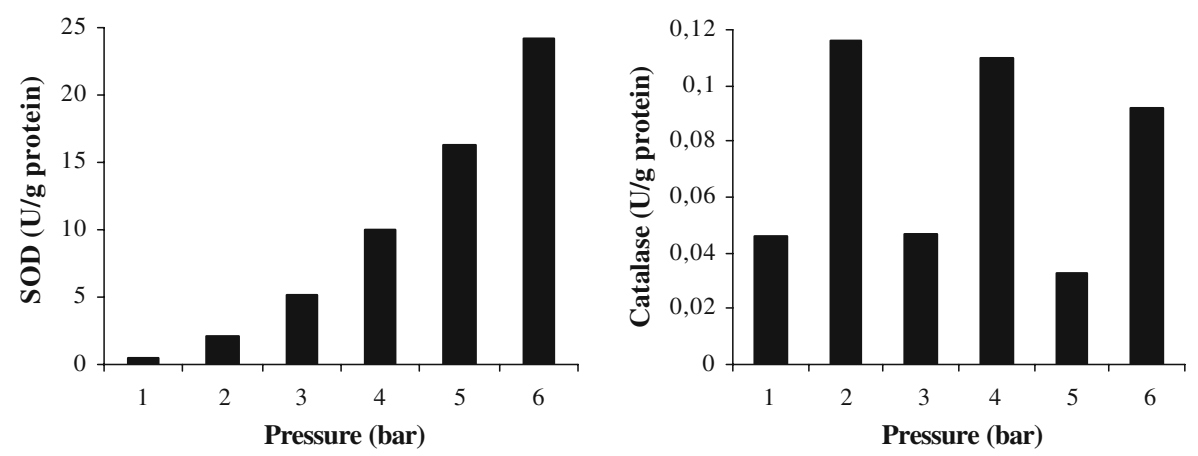

Fig. 2 Effect of air pressure on superoxide dismutase and catalase-specific activities in the final batch cell cultures (approximately $30 \mathrm{~h}$ of growth) 
Fig. 3 Extracellular lipase activity profiles by $Y$. lipolytica during batch experiments with preadaptation to hyperbaric conditions: growth at 1 bar and production at 1 bar (filled diamonds), 1 and 5 bar (filled squares), 5 and 1 bar (filled triangles), and 5 and 5 bar (x marks)

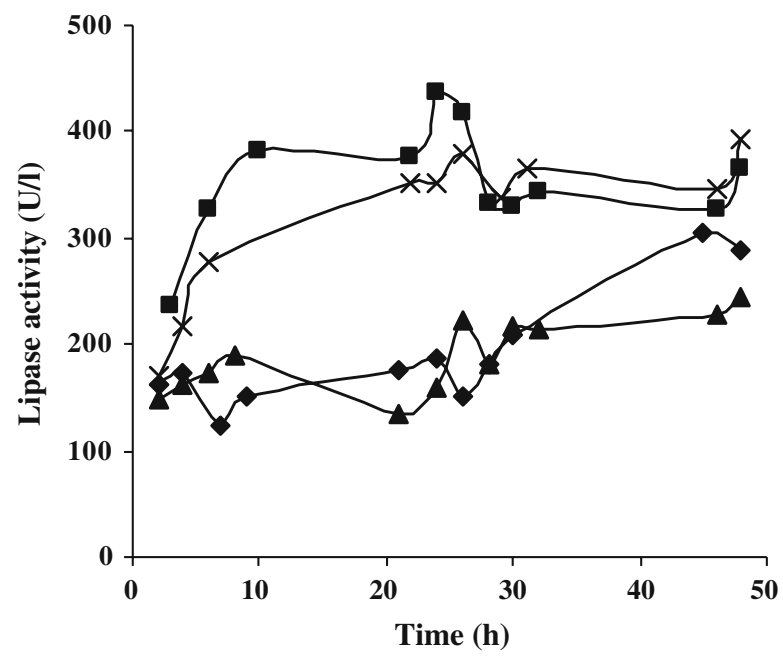

Pressure Effect on Lipase Production and Preadaptation

In order to investigate the influence of a preadaptation phase of cells to hyperbaric conditions on the lipase production by Y. lipolytica cells under increased pressure, assays were conducted in the pressurized bioreactor in which cells were pregrown on the bioreactor at normal and increased pressure followed by a lipase production phase at normal and increased pressure.

The increase of total air pressure influences enzymatic activity, as demonstrated by the previous work of Lopes et al. [14]. The authors observed that an increase of OTR by raising air pressure up to 8 bar resulted in an increase of the lipase production by Y. lipolytica cells pregrown at atmospheric pressure. In this work, an increase of the lipase activity and lipase productivity at 5 bar of 1.8 -fold and 3.7-fold, respectively, was obtained compared with the experiments under 1 bar (Fig. 3).

For the range of air pressure values applied, the preadaptation phase of cells to hyperbaric conditions did not improve the lipase production. The lipase production at 5 bar with cells pregrown at the same air pressure was similar to that obtained with cells grown

Fig. 4 Protease activity profiles by $Y$. lipolytica in the pressurized reactor at different air pressures of growth and production, respectively: 1 and 1 bar (filled diamonds), 1 and 5 bar (filled squares), 5 and 1 bar (filled triangles), and 5 and 5 bar (x marks)

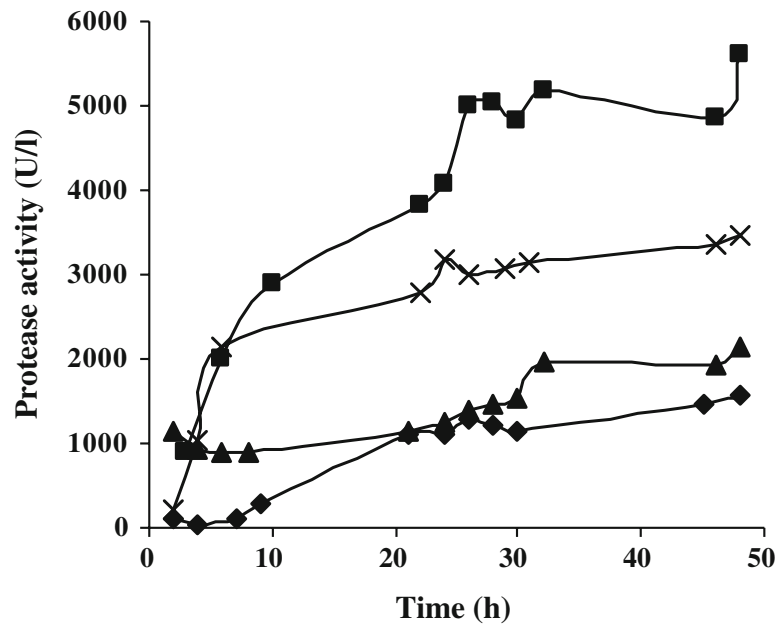


under 1 bar. This indicates that responses of the cells, in what lipase production is concerned, occur irrespective of the preculture pressure conditions. Therefore, it can be concluded that the $Y$. lipolytica cells can quickly respond and adapt to hyperbaric conditions and no need of long phases of hyperbaric stress adaptation is needed. Contrary to this result, it was previously observed that pregrowth of Y. lipolytica W29 under 1 or 5 bar of air pressure had a strong influence in the activities of enzymes of the $\beta$-oxidation pathway of the methyl ricinoleate biotransformation to decalactones leading to considerable differences in metabolites production at 1 or 5 bar of total air pressure [3].

Besides lipase production, the production of other enzymes, such as proteases, by $Y$. lipolytica strains has been reported [22]. In spite of the fact that the culture medium conditions used favor lipase production, protease activity was detected in the medium. Figure 4 shows the results of monitoring protease secretion along time. During the first hours of culture, the protease activity was low, increasing gradually until the end of the cultivation time, suggesting that the decrease of the medium $\mathrm{pH}$ (data not shown) favors the production of an acid protease by yeast.

The highest value of protease production was found for the 5-bar assays, whereas in the experiments carried out under 1 bar its concentration in the medium was lower. The presence of protease in culture medium can influence the production kinetics of lipases since the prolonged time of fermentation can lead to the loss of product due to its decomposition. In this work, highest value of protease production was reached at the same air pressure ( 5 bar) that the maximum lipase productivity was obtained but the preexposition of cells to increased air pressure reduced $40 \%$ the protease activity, leading to a decrease of the ratio between lipase and protease activities from 0.12 to 0.08 .

\section{Conclusions}

For the experimental conditions used in this work, air pressure rise up to 6 bar proved to be applicable to the batch cultivation of Y. lipolytica W29. It has been demonstrated that the use of air pressure has positive effects on the growth behavior of the yeast and that air pressure may be a way of improving oxygenation and consequently increase the specific growth rate, leading to high biomass productivity. For Y. lipolytica, an increase of air pressure up to 6 bar led to a 4.1-fold improvement in biomass productivity compared to atmospheric pressure.

To protect against the damage caused by oxidative stress, cells possess a number of antioxidant enzymes and repair activities, most of which are expressed at low levels during normal growth. In spite of the SOD induction, air pressure raise did not inflict oxidative stress to the cells. Y. lipolytica W29 adapts rapidly to hyperbaric conditions; thus, these conditions can be imposed to cultures of this strain as a way of preventing oxygen limitation to cell growth and as a mean of enzyme production improvement such as lipases and SOD. Air pressure can be seen as an important operating parameter such as medium composition [19] and strain selection [23] for lipase production optimisation.

\section{References}

1. Barth, G., \& Gaillardin, C. (1996). In K. Wolf (Ed.), Nonconventional yeasts in biotechnology (pp. 313388). Berlin, Germany: Springer-Verlag.

2. Zvyagilskaya, R., Andreishcheva, E., Soares, M. I. M., Khozin, I., Behre, A., \& Persson, B. L. (2001). Journal of Basic Microbiology, 41, 289-303. 
3. Aguedo, M., Gomes, N., Garcia, E. E., Waché, Y., Mota, M., Teixeira, J. A., et al. (2005). Biotechnology Letters, 27, 1617-1621.

4. Knoll, A., Bartsch, S., Husemann, B., Engel, P., Schroer, K., Ribeiro, B., et al. (2007). Journal of Biotechnology, 132(2), 167-179.

5. Charoenrat, T., Ketudat-Cairns, M., Jahic, M., Veide, A., \& Enfors, S.-O. (2006). Biochemical Engineering Journal, 30, 205-211.

6. Knoll, A., Maier, B., Tscherrig, H., \& Buchs, J. (2005). Advances in Biochemical Engineering Biotechnology, 92, 77-99.

7. Onken, U., \& Liefke, E. (1989). Advances in Biochemical Engineering Biotechnology, 40, 137-169.

8. Izawa, S., Inoue, Y., \& Kimura, A. (1995). FEBS Letters, 368, 73-76.

9. Moradas-Ferreira, P., Costa, V., Piper, P., \& Mager, W. (1996). Molecular Microbiology, 19, 651-658.

10. Belo, I., Pinheiro, R., \& Mota, M. (2003). Biotechnology Progress, 19, 665-671.

11. Pinheiro, R., Belo, I., \& Mota, M. (2000). Enzyme and Microbial Technology, 26, 756-762.

12. Beers, R. F., \& Sizer, I. W. (1952). Journal of Biological Chemistry, 195, 276-287.

13. Marklund, S., \& Marklund, G. (1974). European Journal of Biochemistry, 47(3), 469-474.

14. Lopes, M., Gomes, N., Gonçalves, C., Coelho, M. A. Z., Mota, M., \& Belo, I. (2008). Letters in Applied Microbiology, 46, 255-260.

15. Pinheiro, R., Belo, I., \& Mota, M. (1997). Biotechnology Letters, 19(7), 703-708.

16. L'italien, Y., Thibault, J., \& LeDuy, A. (1989). Biotechnology Letters, 15, 189-194.

17. Matsui, T., Shinzato, N., Yokota, H., Takahashi, J., \& Sato, S. (2006). Process Biochemistry, 41(4), 920924.

18. Han, J., \& Zhong, J.-J. (2003). Enzyme and Microbial Technology, 32(3-4), 498-503.

19. Amaral, P. F. F., de Almeida, A. P., Peixoto, T., Rocha-Leão, M. H. M., Coutinho, J. A. P., \& Coelho, M. A. Z. (2007). World Journal of Microbiology \& Biotechnology, 23, 339-344.

20. Kawasse, F. M., Amaral, P. F., Rocha-Leão, M. H. M., Amaral, A. L., Ferreira, E. C., \& Coelho, M. A. Z. (2003). Bioprocess and Biosystems Engineering, 25, 371-375.

21. Biryukova, E. N., Medentsev, A. G., Arinbasarova, A. Y., \& Akimenko, V. K. (2006). Microbiology, 75 (3), 243-247.

22. Puthli, M. S., Rathod, V. K., \& Pandit, A. B. (2006). Biochemical Engineering Journal, 27, $287-294$.

23. Destain, J., Fickers, P., Weekers, F., Moreau, B., \& Thonart, P. (2005). Applied Biochemistry and Biotechnology, 121(1-3), 269-277. 